\title{
Maternal and Fetal Outcome of Pregnancy with COVID- 19 in A Tertiary Level Hospital, Bangladesh
}

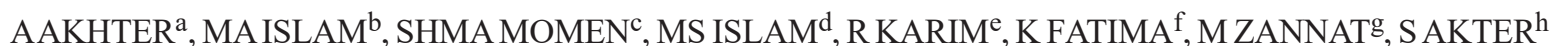

\begin{abstract}
:
Introduction: Pregnant women have long been recognized as a vulnerable population during infectious disease pandemics due to physiological changes in the immune, pulmonary, cardiac and coagulation systems. It is essential to acquire knowledge of pregnancy outcomes, potential complications and neonatal health conditions born to an infected mother with COVID-19.

Material and methods: This cross-sectional observational study was conducted in Combined Military Hospital (CMH), Jashore from June 2020 to July 2021 among 100 hospitalized laboratory-confirmed COVID-19 positive pregnant women, patients who had clinical symptoms of COVID but RT PCR negative were excluded. The aim of the study was to evaluate the clinical profile and maternal and fetal outcome of pregnancy. Relevant data were recorded in a preformed data collection sheet and analyzed by SPSS version 20.
\end{abstract}

Results: Among 100 COVID-19 positive hospitalized pregnant women, the mean age of participants was 27 years (range 19-40 years), Maximum infection rate observed during 12 to 28 weeks of gestation among the participants, $21 \%$ got infected at 37 to 40 weeks of gestation and $20 \%$ got infected at 32 to 36 weeks. Seventy-four percent patients underwent delivery during the study \& $23 \%$ of them continued with ongoing pregnancy; 67 of the participants underwent LUCS and 7 vaginal deliveries were done, 3\% had abortion and

a. Colonel Afroza Akhter, Classified Specialist, CMH Jashore

b. Brigadier General Md. Aminul Islam (Retd),

c. Dr. Shahjad Hossain Md. Al Momen, Assistant Professor, Kurmitola General Hospital

d. Lieutenant Colonel Munshi Sariful Islam, Classified Specialist, CMH Jashore

e. Lieutenant Colonel Rehnuma Karim, Classified Specialist, $\mathrm{CMH}$ Jashore

f. Lieutenant Colonel Kaniz Fatema, Classified Specialist, $\mathrm{CMH}$ Jashore

g. Major Mahmuda Zannat, Classified Specialist, CMH Jashore

h. Major Shamima Akter, Graded Specialist, CMH Jashore

Address of Correspondence: Colonel Afroza Akhter, Classified Specialist, CMH Jashore.

Mobile: 01769014854, Email: majorafroza@gmail.com

Received: 20 Sept., 2021

Accepted: 27 Nov., 21
IUFD 1\%,61\% were multipara and $39 \%$ were Primipara, associated co-morbidities were subclinical hypothyroidism(15\%), pregnancy induced HTN(12\%) and GDM(8\%); $36 \%$ participants were asymptomatic and $44 \%$ had mild symptoms, rate of LUCS was higher than (90.64\%) vaginal delivery. Among the 73 live births, $80.82 \%$ were term and $10.18 \%$ were preterm of neonates, small for gestational was seen in the case of $20.55 \%$ neonates. Testing for $S A R S-C o V-2$ was performed in all neonatal throat swabs and found positive in one case only. Eighty-six percent neonates were well-baby and $9.58 \%$ neonates required NICU admission. There were 2 neonatal deaths due to severe prematurity and 2 babies were found to have congenital cardiac anomaly and cleft lip, cleft palate. Though $36 \%$ of patients were asymptomatic but $10 \%$ were severe and in the critical stage. HDU support needed for $8 \%$ of patients and ICU support for $6 \%$.

Conclusion: This cross-sectional study supports that pregnant women with COVID-19 infection are at increased risk of adverse pregnancy and birth outcomes and a low risk of congenital transmission. Availability of ICU in critical conditions is needed for better pregnancy outcomes.

Keywords: Corona virus, Outcome, Pregnancy, Severe acute respiratory syndrome

(J Bangladesh Coll Phys Surg 2022; 40: 10-16)

DOI: https://doi.org/10.3329/jbcps.v40i1.57058

Introduction:

COVID-19 is a potentially severe acute respiratory infection caused by novel evolving severe acute respiratory syndrome coronavirus 2 (SARS-CoV-2) and declared as a pandemic disease by World Health Organization (WHO) 1, can present with mild infection to severe illness to fatal illness2. Several groups are susceptible to being infected with COVID-19, like the elderly, children, and pregnant women3,4.

Physiologic changes in the immune and cardiopulmonary systems render pregnant women more susceptible to respiratory pathogens5. Studies have shown that pregnant women are at an increased risk for severe illness and adverse pregnancy outcomes from COVID-19 compared to non-pregnant women6, 
rendering more hospitalization7and a higher risk of complications in later trimesters of the pregnancy8.

There is currently no evidence that the virus can be transmitted to the fetus during pregnancy and during childbirth. It is essential to acquire knowledge of pregnancy outcomes, including the symptoms severity, potential complications, and the neonatal health conditions born to a COVID-19 infected mother.

\section{Materials and Methods:}

This cross-sectional observational study was conducted at the tertiary care 500 bed Combined Military Hospital (CMH), Jashore, from June 2020 to July 2021. The protocol was approved by the Ethical and Scientific Committee of their situation. A total of 100 pregnant women with COVID-19 confirmed by RT PCR were enrolled as the study subject. Patients who had clinical symptoms of COVID but RT PCR negative were excluded. Data were collected in a preformed data collection sheet through convenient sampling. Appropriate written informed consent was obtained from every patient according to their visited Declaration of Helsinki. Demographic data (age, para, etc.), clinical data (symptoms on admission, comorbidities, etc.), and pregnancy outcome data (both maternal and neonatal) were collected. Statistical analysis was carried out using the Statistical Package for Social Sciences version 22.0 for Windows (SPSS Inc., Chicago, Illinois, USA Results:

Among the COVID-positive 100 pregnant women, the mean age was 27 years $(\mathrm{SD} \pm 5$ ) (range $19-40$ years). The highest $31 \%$ patients belonged to the $26-30$ years age group, 29\% belonged to the 31-35 year age group, $24 \%$ to $19-25$ year and $16 \%$ to $36-40$ year age group (Fig-I).

The reported clinical symptoms on admission were fever(53\%), shortness of breath (SOB) (42\%),

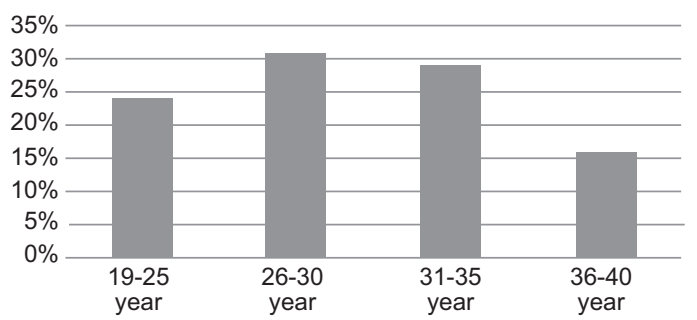

Fig.-1: Age distribution of the participants $(N=100)$ cough $(38 \%)$, myalgia $(29 \%)$, malaise $(25 \%)$, sore throat (25\%), anosmia (12\%) (Fig-II). All patients were nursed in COVID-19 ward and HDU/ICU. Escalated oxygen flow was given as per patients' $\mathrm{SpO}_{2}$ and degree of respiratory distress.

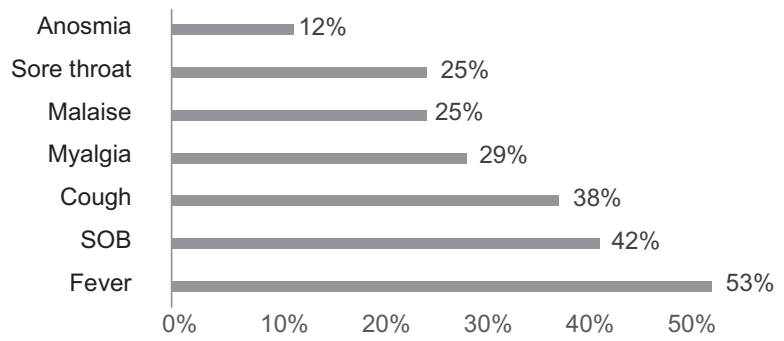

Fig.-2: Frequency of presenting symptoms of the COVID infected pregnant women $(N=100)$

Table-I showed the demographic characteristics and comorbidities of the participants. Sixty-one percent of participants were multipara, and 39\% were primipara. Fifteen percent of them had subclinical hypothyroidism, $12 \%$ had pregnancy-induced HTN, and $8 \%$ had gestational diabetes mellitus.

Clinical characteristics of the pregnant women are shown in Table II. The highest $44 \%$ of our study subjects presented with mild symptoms, and $36 \%$ of them were asymptomatic. Only $4 \%$ of patients presented with severe pneumonia and $6 \%$ were grouped as critical cases.

Maximum infection rate observed during 12 to 28 weeks of gestation among the participants ( Table-III). Twenty one percent of women got infected at 37 to 40 weeks of gestation and $20 \%$ got infected at 32 to 36 weeks.

The frequency of adverse pregnancy outcomes was low in our study, $74 \%$ of patients underwent delivery during the study \& $23 \%$ of them continued with ongoing pregnancy. Three percent of the pregnancies were aborted, and one intrauterine fetal death was observed, in which case the mother had uncontrolled GDM (Table IV)

The rate of lower uterine caesarean section was high among the participants (90.64\%), only $9.46 \%$ of women gave birth by vaginal delivery (Fig-I)

Among the 67 patients who had undergone LUCS, the indication of surgery was previous LUCS in $67.17 \%$ cases and fetal distress in $28.36 \%$ cases. Other indications were prolonged labor (2.98\%) and cephalo- 
Table-I

Demographic characteristics and co morbidity of pregnant women with COVID-19 (N=100)

\begin{tabular}{llcc} 
General Characteristics & & $\mathrm{n}$ & Frequency (\%) \\
\hline Parity & Multipara & 61 & $61 \%$ \\
& Primipara & 39 & $39 \%$ \\
Pregnancy associated & Hypothyroidism (Subclinical) & 15 & $15 \%$ \\
co-morbidities & Pregnancy Induced Hypertension & 12 & $12 \%$ \\
& Gestational diabetes mellitus & 8 & $8 \%$ \\
\hline
\end{tabular}

\section{Table-II}

Clinical characteristics of pregnant women with COVID-19 $(N=100)$

\begin{tabular}{|c|c|c|c|}
\hline Classification & Definition & $\mathrm{n}$ & Percentage $(\%)$ \\
\hline Asymptomatic & No symptom but test + ve & 36 & $36 \%$ \\
\hline $\begin{array}{l}\text { Mild case with } \\
\text { Influenza-like illness }\end{array}$ & $\begin{array}{l}\text { The Clinical symptom is } \\
\text { mild there is no evidence } \\
\text { of pneumonia }\end{array}$ & 44 & $44 \%$ \\
\hline Moderate case (Pneumonia) & $\begin{array}{l}\text { Clinical sign of } \\
\text { pneumonia but no sign of } \\
\text { severe pneumonia } \mathrm{SpO}_{2} \\
>94 \% \text { on room air }\end{array}$ & 10 & $10 \%$ \\
\hline $\begin{array}{l}\text { Severe case } \\
\text { Severe Pneumonia }\end{array}$ & $\begin{array}{l}\text { Clinical sign of } \\
\text { pneumonia plus } \mathrm{SpO}_{2} \\
<94 \% \text { on room air }\end{array}$ & 4 & $4 \%$ \\
\hline Critical case & $\begin{array}{l}\text { Severe COVID-19 case } \\
\text { meeting any of the } \\
\text { following criteria. } \\
\text { - Respiratory failure requiring } \\
\text { - mechanical } \\
\text { - ventilation } \\
\text { - Sepsis. } \\
\text { - ARDS } \\
\text { - Any organ failure } \\
\text { - } \text { requires ICU care }\end{array}$ & 6 & $6 \%$ \\
\hline
\end{tabular}

Table-III

Gestational age at which the pregnant women acquired COVID infection $(N=100)$

Gestational agein weeks No of Patients Percentage

\begin{tabular}{lll}
\hline Before 12 & 12 & $12 \%$ \\
$12-28$ & 29 & $29 \%$ \\
$28-32$ & 18 & $18 \%$ \\
$32-36$ & 20 & $20 \%$ \\
$37-40$ & 21 & $21 \%$ \\
\hline
\end{tabular}

Table-IV

Pregnancy outcome of pregnant women with COVID-19 $(N=100)$

\begin{tabular}{lcc} 
Maternal outcome & $\mathrm{n}$ & Frequency (\%) \\
\hline Delivery & 74 & $74 \%$ \\
Ongoing Pregnancy & 23 & $23 \%$ \\
Abortion & 3 & $3 \%$ \\
Intrauterine fetal death (IUFD) & 1 & $1 \%$ \\
\hline
\end{tabular}




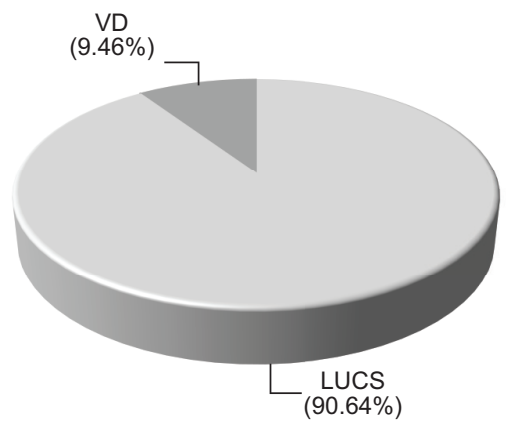

Fig.-3: Mode of delivery of pregnant women with COVID-19 $(n=74)$

Table-V

\begin{tabular}{lcc}
\multicolumn{3}{c}{ Indications of Caesarean Section $(n=67)$} \\
Indication & Frequency & Percentage \\
\hline Previous Caesarean Section & 45 & $67.17 \%$ \\
Fetal Distress & 19 & $28.36 \%$ \\
Prolonged labor & 2 & $2.98 \%$ \\
Cephalo-Pelvic Disproportion & 1 & $1.49 \%$ \\
\hline
\end{tabular}

Table-VI

\begin{tabular}{|c|c|c|c|}
\hline \multicolumn{4}{|c|}{ Fetal and neonatal Outcome of pregnant women with COVID-19 (n=73) } \\
\hline Outcome & Variables & Frequency & Percentage \\
\hline \multirow[t]{6}{*}{ Fetal Outcome } & Term & 59 & $80.82 \%$ \\
\hline & Preterm & 14 & $10.18 \%$ \\
\hline & Small for Gestational age & 15 & $20.55 \%$ \\
\hline & Average birth weight for gestational age & 55 & $75.34 \%$ \\
\hline & Large for gestational age & 03 & $4.11 \%$ \\
\hline & Intra uterine fetal death (IUFD) & 01 & $0.73 \%$ \\
\hline \multirow[t]{5}{*}{ Neonatal outcome } & Live birth & 73 & $98.65 \%$ \\
\hline & Neonatal COVID-19 infection & 01 & $1.37 \%$ \\
\hline & Hospital admission for NICU support & 07 & $9.58 \%$ \\
\hline & Healthy neonate & 63 & $86 \%$ \\
\hline & Neonatal death & 02 & $2.74 \%$ \\
\hline
\end{tabular}

pelvic disproportion (1.49\%) (Table-V). Inj. Ceftriaxone, Inj. Metronidazole followed by

Oral Cefixime and Metronidazole was used in all patients who underwent cesarean section. Other antibiotics used were Colistin, Moxifloxacin, and Azithromycin in severe infection. Furthermore, Inj. Remdesivir, Inj. Tocilizumab, Inj. Methylprednisolone was used in 10 patients with severe symptoms. Low molecular weight Heparin and postnatally oral Rivaroxaban were used in 20 patients for thromboprophylaxis antenatally. Patients were discharged after being febrile without antipyretic such as paracetamol and significant improvement in respiratory symptoms for 03 days.

Table-VI has shows the neonatal outcome of the participants. Among the 73 live births, $80.82 \%$ were term, and $10.18 \%$ were preterm neonates. Small for gestational age was seen in the case of $20.55 \%$ of neonates. Testing for SARS-CoV-2 was performed in all neonatal throat swabs and found positive in one case only. $86 \%$ of neonates were healthy babies, and $9.58 \%$ of neonates required NICU admission. There were two neonatal deaths due to severe prematurity, and two babies were found to have congenital cardiac anomaly and cleft lip, cleft palate.

\section{Discussion:}

SARS-COV-2 is responsible for causing novel coronavirus disease of 2019 (COVID-19), a multisystem disease ranging in severity from asymptomatic to fatal9. The immunological response to covid-19, like other viruses, relies on a working immune system COVID-19 infection and can result in mild disease in which the virus is cleansed effectively by the immune system or severe disease with a high mortality rate. During pregnancy, women undergo significant physiological 
and immunologic alterations to support and protect the developing fetus. This change can increase the risk of infection with respiratory viruses for pregnant individuals and their fetuses ${ }^{10}$.

The current study summarizes the maternal and neonatal profiles and pregnancy outcomes for 100 laboratoryconfirmed COVID-positive mothers in CMH, Jashore. The mean age of the participants was 27 in this study, which is consistent with some other studies conducted in Bangladesh ${ }^{11,12}$, possibly due to Bangladesh having a large youth population.

Association with comorbidities appears to worsen pregnancy outcomes in women with COVID-1913. Women with COVID-19 diagnosis, already at high risk of preeclampsia and COVID-19 because of preexisting overweight, diabetes, hypertension, and cardiac and chronic respiratory diseases, 28 had almost four times greater risk of developing preeclampsia or eclampsia, which could reflect the known association with these comorbidities or the acute kidney damage that can occur in patients with COVID-1914. Associated comorbidities found in our study were subclinical hypothyroidism (15\%), pregnancy-induced HTN(12\%), and GDM( $8 \%$ ). Knowledge about the association of comorbidities in COVID-positive pregnant women is important for appropriate management of severe pregnancy complications, ICU admission or timely referral to a higher level of care, and infections requiring antibiotics, as well as preterm birth and low birth weight.

Early reports suggest that the severity category proportions in the pregnant population are similar to those described for non-pregnant adults with COVID19 infection $1^{5}$. Thirty-six percent of our study subjects were asymptomatic, and $44 \%$ presented with mild COVID symptoms. Fever(53\%), cough (34\%), malaise (13\%), myalgia $(10 \%)$, and shortness of breath $(10 \%)$ were reported maternal symptoms at the time of admission, which is consistent with other studies ${ }^{13,16,17,18}$. Yang et al. conducted a study at a non-designated hospital of Wuhan on 13 pregnant women with Corona infection, where most of the women were observed asymptomatic and had milder symptoms of prenatal fever (15.4\%), postpartum fever (61.6\%), and coughing cases $(15.4 \%)^{20}$. Similarly, a systematic review reported by Ashraf et al. also revealed that the most common symptoms among pregnant women included cough ( $\mathrm{n}$ $=34)$, fever $(\mathrm{n}=47)$, and dyspnea ${ }^{21}$.
Lower uterine cesarean section was higher as a mode of delivery among the participants $(90.64 \%)$ in the present study. Even higher rates of LUCS were reported by Rahman et al.(84.6\%) and Mustafa et al. (79\%) in two recent similar studies in Bangladesh ${ }^{11,12}$. Liu et al. found that $38.0 \%$ of patients required cesarean section in their study22. The meta-analysis of Dubey et al. has reported the rate of C-section was $91 \%$ in Chinese studies, $40 \%$ in the US studies, and 38\%in European studies ${ }^{12}$. A systematic review conducted by Della Gatta et al. reported that $90.2 \%$ of women delivered by Caesarean section23. Indication of higher cesarean sections may be pregnancy complications, including fetal distress, premature rupture of the membrane, and stillbirth, which requires further investigations with a larger sample size.

The most commonly reported adverse outcome of pregnancy with COVID was preterm delivery and increased prevalence of low birth weight ${ }^{24}$. Other obstetric complications and outcomes include maternal death, stillbirth, miscarriage, preeclampsia, fetal growth restriction, premature rupture of membranes, rare but apparent. Stillbirth may become more common as a direct or indirect consequence of the pandemic ${ }^{25}$. In our study, $10.18 \%$ were preterm neonates, which is higher than the national average (10\% in 2018). A recent systematic review of 33 studies described the outcomes of 385 pregnant women with COVID-19 with gestational age at birth ranging from 30 to 41 weeks and a preterm birth rate of $15.2 \%{ }^{26}$.

Intrauterine transmission of SARS-CoV-2 is highly speculative and requires additional evidence to confirm the postulated mechanism of transmission. Elevated IgM antibodies in neonates with SARS-CoV-2 infection born to SARS-CoV-2 positive mothers were identified at two hospitals in Wuhan, China ${ }^{27,28}$. In the present study, $63 \%$ of neonates were born asymptomatic, and without any complications, one of the neonates was COVID-19 positive, which finding is consistent with some recently published studies ${ }^{13,29,30}$. This suggests a good neonatal outcome in pregnant women with SARS-CoV-2 infection. But the possibility of vertical transmission can not be excluded as that fetuses and newborns might show a response, often subclinical, to maternal infection. Furthermore, neonates can acquire SARS-CoV-2 in the postpartum period (horizontal transmission), similar to adults. 
This was a single-center, descriptive study with no selection bias. All the pregnant women were classified based on mild, moderate, and severe symptoms. RTPCR was used for confirming positive results, which is the gold standard. This study can contribute importantly to the sparse data presently available regarding COVID-19 in pregnant patients in a developing country like Bangladesh.

This study has some limitations as well. First, the sample size was limited. Second, there was no control group to compare the result with. Further large-scale, multi-centric studies with larger sample sizes are expected to determine the management protocols at the time of delivery to inhibit the transmission and complications of infection in the mothers and neonates.

\section{Conclusion:}

Pregnant women with COVID-19 infection are more likely to develop maternal complications than non-infected pregnant women, but the transmission of the disease from mother to child is insignificant. For the infected mothers- clinical supervision is important, and ICU facilities also must be readily available. Further resources should be directed towards quality epidemiological studies to better understand the relation between COVID-19 infection and maternal and fetal complications.

\section{References:}

1. National Guidelines on Clinical Management of Corona virus Disease 2019 (COVID-19), Version 7.0, 28 May 2020, Disease Control Division, Directorate General of Health Services Ministry of Health \& Family Welfare Government of the People's Republic of Bangladesh

2. Suleyman G, Fadel RA, Malette KM, Hammond C, Abdulla H, Entz A. Clinical characteristics and morbidity associated with coronavirus disease 2019 in a series of patients in metropolitan detroit. JAMA Netw Open [Internet]. 2020; 3 (6): e2012270. JAMA. 2020;323: 2052

3. Aditya R, Fitria Y. Hubungan Tingkat Kecemasan dan Pengetahuan Ibu Hamil Tentang Antenatal Care Saat Pandemi Covid-19. InSeminar Nasional Psikologi UM 2021 (Vol. 1, No. 1, pp. 437-443).

4. Ri K. Pedoman Pencegahan dan Pengendalian Coronavirus Disease (COVID-19). Kemenkes RI, 0-115. 2020.

5. Yan J,Guo J, Fan C, et al.Coronavirus disease 2019 (COVID19) in pregnanat women: a report based on 116 cases.Am J Obstet Gynecol2020;223:111..e1-14

6. Investigating the impact of COVID-19 on pregnancy: https:/ /www.cdc.gov/coronavirus/2019-ncov/cases-updates/ special-populations/pregnancy-data-on-covid-19/what-cdcis-doing.html

7. Ellington S, Strid P, Tong VT, Woodworth K, Galang RR, Zambrano LD, Nahabedian J, Anderson K, Gilboa SM. Characteristics of women of reproductive age with laboratory-confirmed SARS-CoV-2 infection by pregnancy status-United States, January 22-June 7, 2020. Morbidity and Mortality Weekly Report. 2020 Jun 26;69(25):769.

8. Badr DA, Mattern J, Carlin A, Cordier AG, Maillart E, El Hachem L, El Kenz H, Andronikof M, De Bels D, Damoisel C, Preseau T. Are clinical outcomes worse for pregnant women ate" 20 weeks' gestation infected with coronavirus disease 2019? A multicenter case-control study with propensity score matching. American Journal of Obstetrics \& Gynecology. 2020 Nov 1;223(5):764-8.

9. Wang C., Horby P.W., Hayden F.G., Gao GF. A novel coronavirus outbreak of global concern Lancet 2020; $395: 470-473$

10. Muralidar S, Ambi SV, Sekaran S, Krishnan UM. The emergence of COVID-19 as a global pandemic: Understanding the epidemiology, immune response and potential therapeutic targets of SARS-CoV-2. Biochimie. 2020;179:85-100. https://doi.org/10.1016/ j.biochi.2020.09.018

11. Mustafa FN, Yasmin N, Islam M, Mehzabin S, Siddique S, Alam S. Pregnancy outcome in covid-19 positive women in a covid dedicated hospital. Journal of Dhaka Medical College. 2020;29(2):153-7.

12. Rahman R, Mustary F. Pregnancy complications in COVID19 positive primigravid patients: a comparative study. BIRDEM Medical Journal. 2020 Dec 27:71-3.

13. Bachani S, Arora R, Dabral A, Marwah S, Anand P, Reddy KS, Gupta N, Singh B. Clinical profile, viral load, maternalfetal outcomes of pregnancy with COVID-19: 4-week retrospective, tertiary care single-centre descriptive study. Journal of Obstetrics and Gynaecology Canada. $2021 \mathrm{Apr}$ $1 ; 43(4): 474-82$.

14. Ronco C, Reis T, Husain-Syed F. Management of acute kidney injury in patients with COVID-19. The Lancet Respiratory Medicine. 2020 Jul 1;8(7):738-42.

15. Smith V, Seo D, Warty R, et al. Maternal and neonatal outcome with COVID-19 infection: a systematic review: PLoS One2020,15:e02341877

16. Huang C, Wang Y, Li X, et al. Clinical feature of patients infected with 2019 novel Coronavirus in Wuhan, China.Lancet 2020;395:497-506

17. Qiao J. What are the risks of COVID-19 infection in pregnant women.Lancet 2020;395:760-2

18. Zhang I, Jiang Y, Wei M,et al. Analysis of pregnancy outcome of pregnant women during the epidemic of new Coronavirus pneumonia in Hubei. Zhongua Fu Chan KeZaZhi 2020;55:166-71 
19. Zaigham M, Anderson O. Maternal and perinatal outcome with COVID-19: a systematic review of 108 pregnancies. Acta Obstet Gynecol Scand2020;99:823-9

20. Zeng L, Xia S, Yuan W, Yan K, Xiao F, Shao J. Neonatal early-onset infection with SARS-CoV-2 in 33 neonates born to mothers with COVID-19 in Wuhan, China [published online ahead of print March 26, 2020]. JAMA Pediatr.

21. Rasmussen SA, Smulian JC, Lednicky JA, Wen TS, Jamieson DJ. Coronavirus disease 2019 (COVID-19) and pregnancy: What obstetricians need to know. Am J Obstetr Gynecol. $2020 ; 222(5): 415-26$

22. Liu Y, Chen H, Tang K, Guo Y. Withdrawn: clinical manifestations and outcome of SARS-CoV-2 infection during pregnancy. The Journal of infection. 2020 Mar 5.

23. Della Gatta AN, Rizzo R, Pilu G, Simonazzi G. COVID19 during pregnancy: a systematic review of reported cases. Am J Obst Gynecol. 2020.

24. Savasi VM, Parisi F, Patanè L, Ferrazzi E, Frigerio L, Pellegrino A, Spinillo A, Tateo S, Ottoboni M, Veronese P, Petraglia F. Clinical findings and disease severity in hospitalized pregnant women with coronavirus disease 2019 (COVID-19). Obstetr Gynecol. 2020;136(2):252-8

25. Khalil A, von Dadelszen P, Draycott T, Ugwumadu A, O'Brien P, Magee L. Change in the Incidence of Stillbirth and Preterm Delivery During the COVID-19 Pandemic. JAMA. 2020;324(7):705-6. https://doi.org/10.1001/ jama.2020.12746

26. Elshafeey F, Magdi R, Hindi N, et al. A systematic scoping review of COVID-19 during pregnancy and childbirth. Int J Gynecol Obstet.2020;150:47-52

27. Zeng H, Xu C, Fan J, Tang Y, Deng Q, Zhang W, Long X. Antibodies in Infants Born to Mothers With COVID-19 Pneumonia. JAMA. 2020;323(18):1848-9. https://doi.org/ $10.1001 /$ jama.2020.4861

28. Dong L, Tian J, He S, Zhu C, Wang J, Liu C, Yang J. Possible vertical transmission of SARS-CoV-2 from an infected mother to her newborn. JAMA. 2020;323(18):1846-8. https://doi.org/10.1001/ jama.2020.4621

29. Saadia Z, Farrukh R, Kanwal S, Shahzad Q. Clinical Profiles, Demographic Features, and Maternal Outcomes among Coronavirus Disease Positive Pregnant Women: A Crosssectional Study. Open Access Macedonian Journal of Medical Sciences. 2021 Jun 25;9(B):486-91.

30. Schwartz DA. An analysis of 38 pregnant women with COVID-19, their newborn infants, and maternal-fetal transmission of SARS-CoV-2: maternal coronavirus infections and regnancy outcomes. Archives of pathology \& laboratory medicine. $2020 \mathrm{Jul} ; 144(7): 799-805$. 